\title{
AVALIAÇÃO DA HIDROGEOLOGIA E HIDROQUÍMICA DO SISTEMA AQÜÍFERO GUARANI (SAG) NO ESTADO DE MATO GROSSO DO SUL
}

\author{
Didier Gastmans ${ }^{1}$ e Chang Hung Kiang ${ }^{2}$
}

Recebido em 25/06/2004, aceito em 13/10/2004

\begin{abstract}
RESUMO
Este trabalho apresenta uma avaliação do comportamento hidrogeológico e hidroquímico do Sistema Aqüífero Guarani (SAG) em sua área de ocorrência no Estado de Mato Grosso do Sul. Mapas potenciométrico e de fácies hidroquímicos do SAG no Estado de Mato Grosso do Sul foram elaborados a partir de informações hidrodinâmicas e hidroquímicas existentes na base de dados da SANESUL. A análise da superfície potenciométrica do SAG, na porção ocidental da Bacia Sedimentar do Paraná, indica a existência de áreas de recarga ao norte e ao sul da área estudada, respectivamente no Estado de Goiás e na divisa do Estado de Mato Grosso do Sul com o território da República do Paraguai, com fluxo direcionado para oeste, em direção às zonas de afloramento das formações constituintes do SAG, e para o centro da Bacia Sedimentar do Paraná, em direção às zonas de maior confinamento do aqüífero. Do ponto de vista hidroquímico, as águas contidas no SAG são principalmente bicarbonatadas cálcicas nas regiões próximas à recarga, passando a sódicas com o aumento do grau de confinamento. Termos magnesianos podem estar associados à contribuição do aqüífero basáltico sotoposto ao SAG.
\end{abstract}

Palavras Chave: Hidrogeologia, Hidroquímica, Sistema Aqüífero Guarani no Estado de Mato Grosso do Sul.

\begin{abstract}
The present study shows an overview of hydrogeology and hydrochemistry of the Guarani Aquifer System in the State of Mato Grosso do Sul, Brazil. Groundwater flow patterns in the western portion of the sedimentary Paraná Basin indicate recharge areas located northwards and southwards of the study area, in the State of Góias state and in the border region of Mato Grosso do Sul and Paraguay. Potenciometric surface and hydrochemistry facies maps for the Guarani Aquifer System in the State of Mato Grosso do Sul were constructed using hydrodynamic and hydrochemical data compiled from SANESUL database. Groundwater flows towards the western outcropping areas and in the confining portions of the aquifer, towards the center of the Paraná Basin. From the hydrochemical point of view, SAG groundwaters can be classified as calcium bicarbonate in the recharge regions changing to sodium bicarbonate with increasing confinement. The magnesium contribution is likely associated to the basalt aquifer overlying SAG.
\end{abstract}

Keywords: Hydrogeology, Hydrochemistry, Guarani Aquifer System in the State of Mato Grosso do Sul, Brazil

\section{INTRODUÇÃO}

O Sistema Aqüífero Guarani (SAG) está inserido no contexto geológico da Bacia Sedimentar do Paraná, estendendo-se pelos territórios brasileiro, argentino, paraguaio e uruguaio, representando um exemplo típico de aqüífero transfronteiriço.

No território brasileiro, ocorre nos estados do Rio Grande do Sul, Santa Catarina, Paraná, São Paulo, Minas Gerais e Mato Grosso do Sul. Neste último, ocupa toda porção centro-leste com área de aproximadamente $213.200 \mathrm{~km}^{2}$, dos quais, cerca de $36.000 \mathrm{~km}^{2}$ correspondem às áreas de afloramento das formações Botucatu e Pirambóia.

Atualmente, o Sistema Aqüífero Guarani representa um importante manancial de fornecimento de água potável para o Estado de Mato Grosso do Sul, respondendo por 25\% do abastecimento de água da população (CHANG, 2001). Vários municípios do Estado possuem sistemas de abastecimento de água sustentados total ou parcialmente pelo SAG, destacando-se Campo Grande, Dourados, Ponta Porã, Cassilândia, Inocência, Camapuã.
Apesar dos diversos estudos visando o aprofundamento do conhecimento sobre o Sistema Aqüífero Guarani, (GILBOA et al., 1976; GALLO; SINELLI, 1980; SILVA, 1983; REBOUÇAS, 1994, ARAÚJO et al., 1995 e 1999; CAMPOS, 2000), são poucos os trabalhos que detalham o comportamento hidrogeológico e hidroquímico do SAG na porção oeste da Bacia do Paraná, mais especificamente no Estado de M ato Grosso do Sul.

A maior concentração de informações ocorre na borda oriental da Bacia, principalmente no Estado de São Paulo, em decorrência de inúmeras perfurações efetuadas para o abastecimento de água potável, o que resultou na maior explotação do SAG.

O presente trabalho tem por objetivo apresentar um panorama das características hidroquímicas e do comportamento hidrogeológico do Sistema Aqüífero Guarani (SAG) no Estado do Mato Grosso do Sul, baseando-se em informações extraídas de estudos prévios.

\footnotetext{
${ }^{1}$ Doutorando, Instituto de Geociências e Meio Ambiente - IGCE - UNESP (gastmans@rc.unesp.br)

2 Departamento de Geologia Aplicada - DGA, Instituto de Geociências e Meio Ambiente - IGCE - UNESP (chang@rc.unesp.br.)
} 


\section{LOCALIZAÇÃO E CARACTERIZAÇÃO DA ÁREA DE ESTUDO}

A área em estudo está localizada na porção centro-leste do Estado de Mato Grosso do Sul, entre as coordenadas $17^{\circ} 30^{\prime}$ e $24^{\circ} \mathrm{N}$ e $51^{\circ}$ e $56^{\circ}$ E (Figura 1), apresentando como limite oeste a faixa de afloramentos das formações Botucatu e Pirambóia, que praticamente divide o Estado ao meio, estendendo-se até as divisas com os Estados de São Paulo a leste, Minas Gerais e Goiás a norte e Paraná a sudeste, além do território da República do Paraguai ao sul.

A porção leste do Estado de Mato Grosso do Sul insere-se no arcabouço geológico da Bacia Sedimentar do Paraná onde se encontram representados os sedimentos arenosos pertencentes às formações Botucatu e Pirambóia, que afloram em uma faixa de direção NNE, com largura variável, na região central do Estado de Mato Grosso do Sul, representando o início do Pantanal Matogrossense, que se estende a oeste da área estudada. Estas unidades são recobertas pelos derrames de rochas basálticas da Formação Serra Geral, que afloram na porção sul da área estudada, e que por sua vez são recobertos pelos sedimentos pertencentes ao Grupo Bauru, aflorantes na porção leste do Estado de Mato Grosso do Sul. Capeando esta sucessão, ocorrem as coberturas terciárias, distribuídas por toda área.

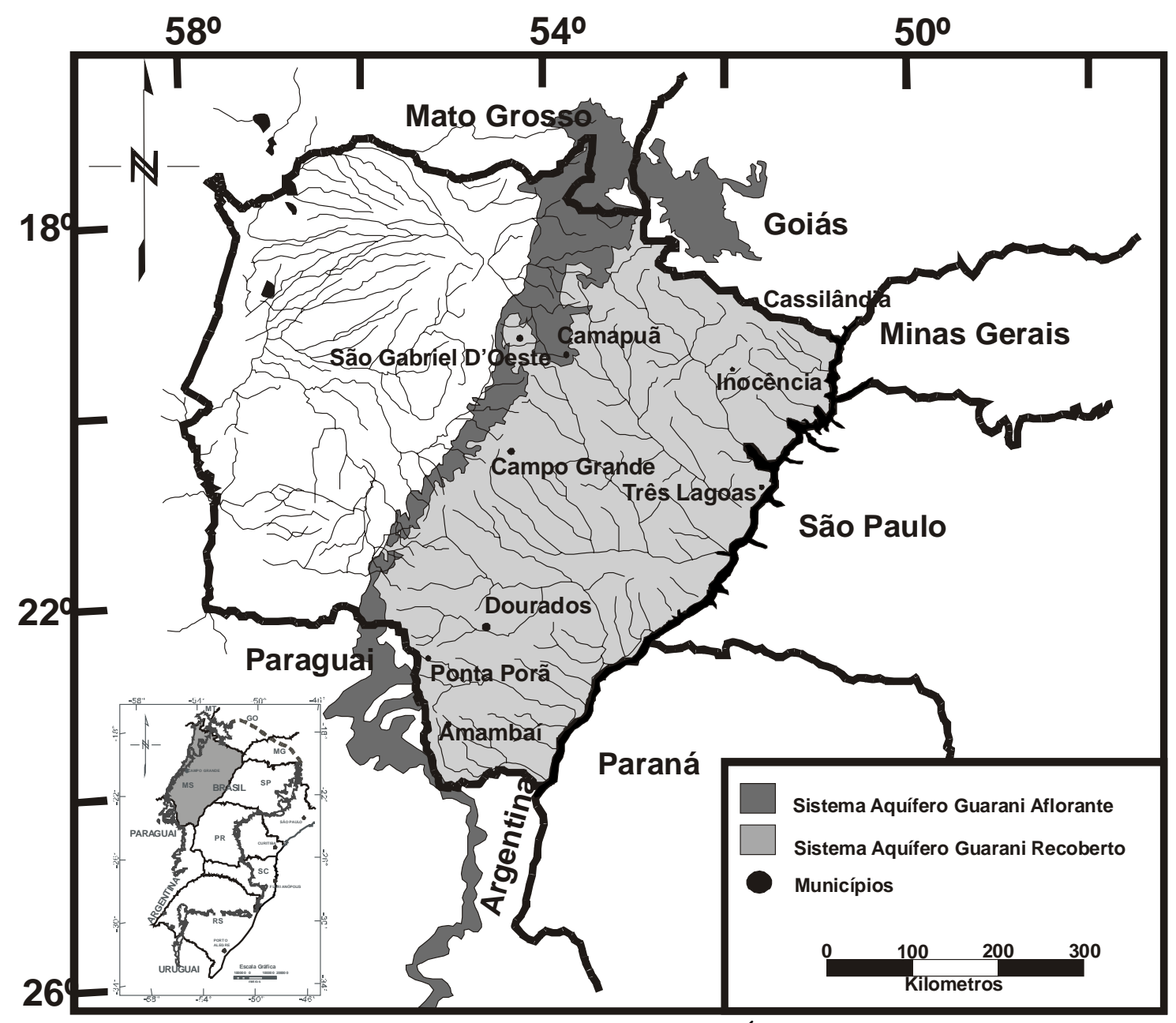

Figura 1 - Mapa de Localização da Área de Estudo

\section{BASE DE DADOS UTILIZADA}

A partir de cadastro de poços tubulares profundos pertencentes às diversas Companhias de Saneamento que atuam no Estado de Mato Grosso do Sul, disponibilizado pela SANESUL, contendo informações relativas ao posicionamento geográfico, de características construtivas e hidrogeológicas dos poços, além de dados hidroquímicos referentes aos Sistemas Aqüíferos Guarani e Serra Geral, foi elaborado o presente trabalho. Esta base de dados foi gerada quando da realização do trabalho intitulado "Estudos Hidrogeológicos de Mato Grosso do Sul", nos anos de 1997-1998, pela Empresa TAHAL Consulting Enginers, em parceria com a SANESUL (SANESUL/TAHAL, 1998). 
O conjunto de dados foi complementado com informações de novos poços perfurados pelas companhias de saneamento, além de poços pertencentes a particulares, que exploram as águas subterrâneas do Sistema Aqüífero Guarani, e de dados existentes em estudos prévios (LASTORIA, 2002).

\section{SISTEMA AQUIFERO GUARANI (SAG)}

O Sistema Aqüífero Guarani constitui aqüífero de dimensões continentais, localizado nas Bacias Sedimentares do Paraná e ChacoParaná, formado pelo conjunto de rochas arenosas das formações triássicas (formações Pirambóia e Rosário do Sul, no Brasil, e Buena Vista no Uruguai) e jurássicas (formações Botucatu, no Brasil, Missiones no Paraguai e Tacuarembó na Argentina e no Uruguai) destas bacias (ARAÚJO et al.., 1995, 1999; GEF, 2001).
Ocupa área aproximada de $1.194 .000 \mathrm{~km}^{2}$, sendo $840.000 \mathrm{~km}^{2}$ em território brasileiro, $225.000 \mathrm{~km}^{2}$ na Argentina, $72.000 \mathrm{~km}^{2}$ no Paraguai e $58.000 \mathrm{~km}^{2}$ em território uruguaio, encontrando-se em quase toda sua extensão sobreposto por rochas basálticas pertencentes à formação Serra Geral, cuja espessura pode chegar a 1000 metros (ARAÚJO et al., 1995).

As principais características hidrodinâmicas do aqüífero são apresentadas na tabela 1 , compiladas a partir de informações contidas nos trabalhos de ARAÚJO et al. (1999) e SRACEK; HIRATA (2002), elaboradas principalmente a partir de informações obtidas nos estados de São Paulo, Paraná e Rio Grande do Sul, onde se concentra a maior parte das informações, reflexo do maior número de poços existentes nestes estados, quando comparados ao restante da área de ocorrência do SAG na Bacia do Paraná.

Tabela 1 - Principais Parâmetros Hidrodinâmicos do SAG

\begin{tabular}{|c|c|c|c|c|}
\hline \multirow{2}{*}{\multicolumn{2}{|c|}{ Parâmetro }} & \multirow{3}{*}{$\begin{array}{c}\text { SAG - São Paulo } \\
\text { (Fonte: SRACEK; } \\
\text { HIRATA, 2002) } \\
550\end{array}$} & \multicolumn{2}{|c|}{$\begin{array}{l}\text { SAG -Bacia do Paraná } \\
\text { (Fonte: ARAUJO et al., 1999) }\end{array}$} \\
\hline & & & \multirow{3}{*}{$\begin{array}{c}\text { Fm. Botucatu } \\
4-484 \\
138\end{array}$} & \multirow{3}{*}{$\begin{array}{c}\text { Fm. Pirambóia } \\
25-770 \\
139\end{array}$} \\
\hline \multirow{2}{*}{$\begin{array}{c}\text { Espessura } \\
\text { (m) }\end{array}$} & Máxima & & & \\
\hline & Média & 268 & & \\
\hline \multicolumn{2}{|c|}{ Porosidade } & $10-15 \%$ & $17-30 \%$ & $14-24 \%$ \\
\hline \multicolumn{2}{|c|}{$\begin{array}{c}\text { Condutividade Hidráulica } \\
\text { média (m/dia) }\end{array}$} & 12,96 & 8,7 & 1,9 \\
\hline \multicolumn{2}{|c|}{ Transmissividade (m²/dia) } & $\begin{array}{l}39-1035 \\
\text { Média } 336\end{array}$ & $2,4-552$ & - \\
\hline \multicolumn{2}{|c|}{$\begin{array}{c}\text { Coeficiente de } \\
\text { Armazenamento }\end{array}$} & $4 \times 10^{-5}-2 \times 10^{-4}$ & - & - \\
\hline
\end{tabular}

O primeiro mapa potenciométrico do SAG foi elaborado por GILBOA et al. (1976), indicando que as áreas de recarga estariam localizadas principalmente nas zonas de afloramento das formações constituintes do aqüífero, com fluxo para o eixo central da bacia, e uma zona de descarga localizada na região sudoeste da Bacia do Paraná, no Estado do Rio Grande do Sul.

Estudos mais recentes, contemplando um maior número de poços perfurados no SAG, apresentam uma nova configuração para a superfície potenciométrica do aqüífero, inclusive discorrendo sobre a influência das grandes estruturas tectônicas existentes na Bacia Odo Paraná, e que de alguma maneira podem influenciar o fluxo das águas subterrâneas no aqüífero, como por exemplo, o Arco de Ponta Grossa (ARAÚJO et al., 1999 e ROSA FILHO et al., 2003).
A ocorrência de inúmeros diques de diabásio associados ao Arco de Ponta Grossa divide o SAG, segundo ARAÚJO et al. (1999), em dois grandes domínios potenciométricos, o primeiro localizado ao norte, apresentando zonas de recarga associadas aos afloramentos das formações Botucatu e Pirambóia, com fluxo de água preferencialmente centrípeto, todo ele em direção ao centro da bacia, e gradientes hidráulicos entre 5 e $3 \mathrm{~m} / \mathrm{km}$ próximo às zonas de afloramento, até $0,2 \mathrm{~m} / \mathrm{km}$, em direção ao centro da bacia.

O segundo domínio hidrogeológico, localizado ao Sul do Arco de Ponta Grossa, apresenta os maiores gradientes hidráulicos ( 5 a $0,3 \mathrm{~m} / \mathrm{km})$, com fluxo direcionado preferencialmente de leste para oeste, com a zona de recarga localizada no Estado de Santa Catarina, e a principal zona de descarga do 
aqüífero situada ao longo dos Rios Paraná e Uruguai, não sendo descartada a ocorrência de descarga ao longo do Rio Pelotas, em Santa
Catarina e no Rio Grande do Sul (ARAÚJO et al., 1999) (Figura 2).

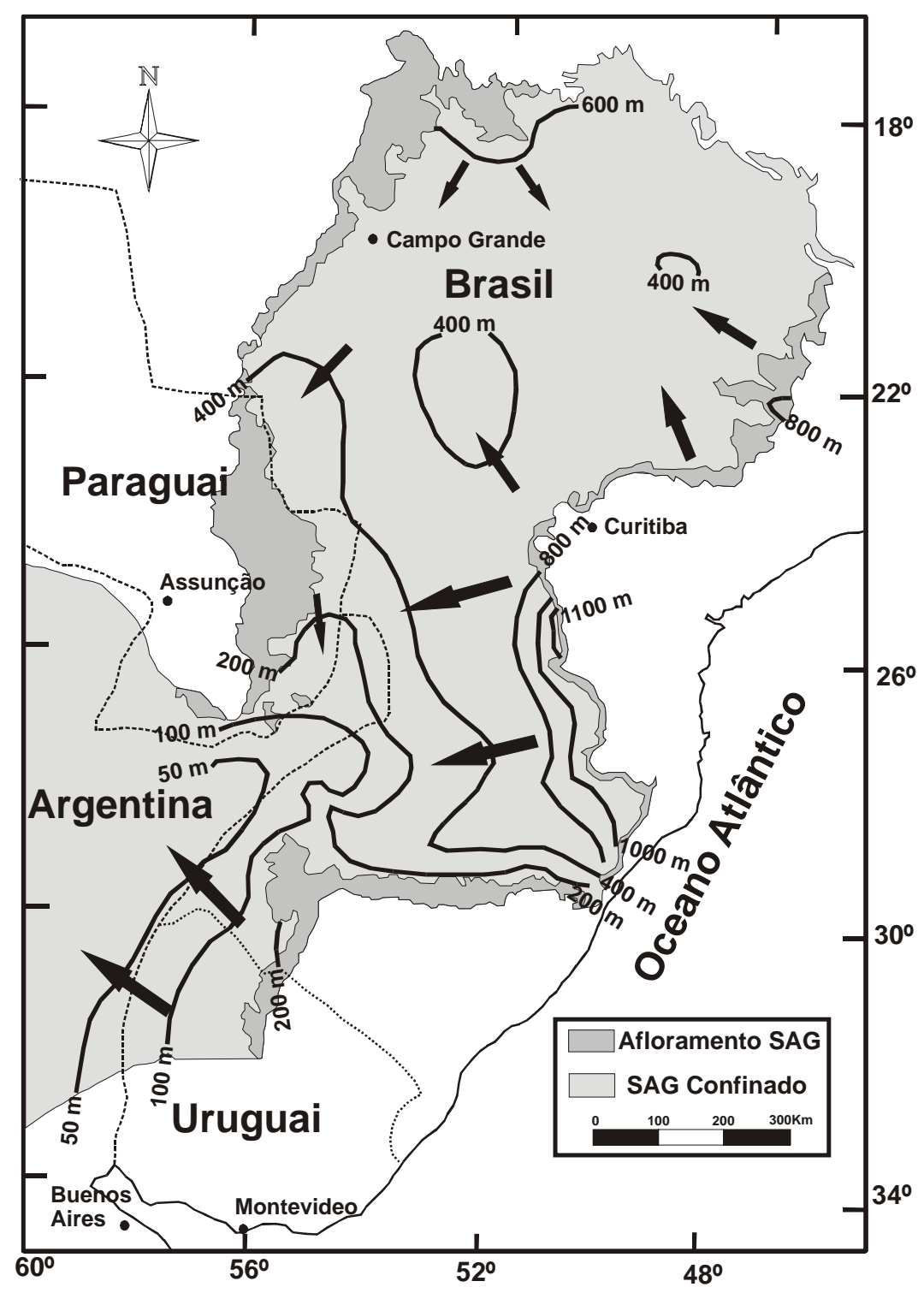

Figura 2 - Mapa Potenciométrico do SAG (Modificado da ARAUJO et al., 1999).

Os principais estudos hidroquímicos para a caracterização das águas do Sistema Aqüífero Guarani foram realizados principalmente no Estado de São Paulo, iniciados com o clássico trabalho de SILVA (1983), cujos dados foram posteriormente retomados por diversos autores (MENG; MAYNARD, 2001 e SRACECK; HIRATA, 2002), visando a elaboração de um modelo da evolução hidroquímica destas águas para a porção nordeste da Bacia do Paraná.

SILVA (1983) divide as águas contidas no SAG, no Estado de São Paulo, em dois grupos principais, divisão esta relacionada principalmente ao grau de confinamento do aqüífero.

Na região de afloramentos, a autora identifica predominância de águas bicarbonatadas magnesianas e cálco-magnesianas. Em direção oeste, numa faixa de cerca de $60 \mathrm{~km}$ de largura a partir do contato da zona de afloramentos das formações Botucatu/Pirambóia com os basaltos da Formação Serra Geral, as águas são bicarbonatadas cálcicas e calco-magnesianas. $\mathrm{Na}$ porção de maior confinamento, localizada a oeste da faixa de afloramentos, próxima à calha do Rio Paraná, as águas tornam-se bicarbonatadas sódicas, evoluindo no extremo sudoeste do estado 
para cloro-sulfatadas sódicas. As principais características hidroquímicas destes dois grupos são apresentadas na tabela 2.

A evolução das águas bicarbonatadas cálcomagnesianas, com ocorrência nas proximidades das zonas de afloramento, para as águas bicarbonatadas sódicas e cloro-sulfatadas nas zonas de maior confinamento do aqüífero, foi estudada por SRACECK; HIRATA (2002). O modelo de troca de cátions (Ca por $\mathrm{Na}$ ) associado a contribuição de íons cloreto e sulfato, provenientes de depósitos evaporíticos contidos na Formação Pirambóia, explicaria esta evolução hidroquímica.

Para o Estado do Paraná, ROSA FILHO et al. (1987) estudando o quimismo das águas subterrâneas contidas nos basaltos do Sistema Aqüífero Serra Geral, observaram em vários pontos a contribuição das águas do SAG na sua composição.

Esta contribuição é facilmente percebida, segundo os autores, pela análise dos cátions maiores, já que as relações características entre os elementos para os dos sistemas aqüiferos são distintas.
A comparação entre a composição química das águas contidas no SAG nos estados do Paraná e São Paulo, e no Uruguai, mostra claramente a existência de tipos sulfatados no estado de São Paulo, que não ocorrem no Paraná, e de tipos cloretados cálcicos no Uruguai que não ocorrem no Brasil (GEF, 2001).

Este fato demonstra claramente a variabilidade do quimismo das águas do SAG, principalmente nas zonas confinadas, o que segundo GEF (2001), pode ser explicado por variações faciológicas ou por influência de misturas induzidas por fraturas tectônicas.

Estudos isotópicos efetuados por diversos autores (GALLO; SINELLI, 1980; SILVA, 1983; KIMMELMANN et al., 1987 e KIMMELMANN et al., 1995) apresentam indicações de possíveis variações climáticas durante diferentes períodos de recarga, e idades das águas baseadas em datações por ${ }^{14} \mathrm{C}$ que variam de 480 até 39.000 anos, estando as águas mais recentes próximas às regiões de afloramento, e as mais velhas localizadas em direção ao centro da bacia.

Tabela 2 - Características das Águas do SAG no Estado de São Paulo (Fonte: SILVA, 1983)

\begin{tabular}{|c|c|c|c|c|}
\hline $\begin{array}{l}\text { Situação do } \\
\text { Aqüífero }\end{array}$ & $\begin{array}{c}\text { Classificação das } \\
\text { Águas segundo } \\
\text { Piper }\end{array}$ & $\begin{array}{c}\text { Faixa de } \\
\text { Ocorrência }\end{array}$ & \multicolumn{2}{|c|}{ Geoquímica das Águas } \\
\hline $\begin{array}{c}\text { Não } \\
\text { Confinado }\end{array}$ & $\begin{array}{l}\text { Bicarbonatadas } \\
\text { Calco - } \\
\text { Magnesianas }\end{array}$ & $\begin{array}{c}\text { Próximo à Faixa } \\
\text { de Afloramentos } \\
\text { (Região Leste do } \\
\text { Estado de São } \\
\text { Paulo) }\end{array}$ & $\begin{array}{c}\text { TDS }<294 \mathrm{mg} / \mathrm{L} \\
\mathrm{pH}<7,5\end{array}$ & $\begin{array}{c}\mathrm{Ca}: 0,04-2,5 \mathrm{meq} / \mathrm{L} \\
\mathrm{Mg}:<1,13 \mathrm{meq} / \mathrm{L} \\
\mathrm{CO}_{3}:<0,04 \mathrm{meq} / \mathrm{L} \\
\mathrm{Cl}:<0,31 \mathrm{meq} / \mathrm{L} \\
\mathrm{Na}:<0,9 \mathrm{meq} / \mathrm{L} \\
\mathrm{HCO}_{3}: 0,06-3,16 \mathrm{meq} / \mathrm{L} \\
\mathrm{SO}_{4}:<0,25 \mathrm{meq} / \mathrm{L}\end{array}$ \\
\hline Confinado & $\begin{array}{l}\text { Bicarbonatadas } \\
\text { Sódicas e Cloro- } \\
\text { Sulfatadas } \\
\text { Sódicas }\end{array}$ & $\begin{array}{l}\text { Regiões Centrais e } \\
\text { Oeste do Estado } \\
\text { de São Paulo }\end{array}$ & $\begin{array}{c}\text { TDS: } 61-650 \\
\text { mg/L } \\
\text { pH: } 8,2-10,4\end{array}$ & $\begin{array}{c}\text { Ca: } 0,02-0,84 \mathrm{meq} / \mathrm{L} \\
\mathrm{Mg}:<0,08 \mathrm{meq} / \mathrm{L} \\
\mathrm{CO}_{3}:<2,9 \mathrm{meq} / \mathrm{L} \\
\mathrm{Cl}: 0,01-3,75 \mathrm{meq} / \mathrm{L} \\
\mathrm{Na}: 0,6-9,8 \mathrm{meq} / \mathrm{L} \\
\mathrm{HCO}_{3}: 0,66-3,4 \mathrm{meq} / \mathrm{L} \\
\mathrm{SO}_{4}:<1,92 \mathrm{meq} / \mathrm{L}\end{array}$ \\
\hline
\end{tabular}

\section{HIDROGEOLOGIA DO SISTEMA AQUÍFERO GUARANI NO ESTADO DO MATO GROSSO DO SUL}

No Estado do Mato Grosso do Sul, o Sistema Aqüífero Guarani é constituído pelas formações Pirambóia e Botucatu, ocupando 213.200 km², dos quais cerca de $36.000 \mathrm{~km}^{2}$ representam as áreas de afloramento destas unidades e, no restante da região, encontram-se sobrepostas pelos basaltos da Formação Serra Geral e por rochas pertencentes ao Grupo Bauru.

A área de afloramento das formações constituintes do SAG ocorre numa faixa de sentido NNS na porção central do Estado de Mato Grosso do Sul, com cerca de 100 km de largura no norte do Estado e estreitando-se em direção ao sul, chegando a desaparecer próximo ao Município de Bela Vista, sendo recoberta 
pelos sedimentos das coberturas terciárias na região de São Gabriel do Oeste.

A leste do Município de Chapadão do Sul, na divisa com o Estado de Goiás, ocorre uma estreita faixa de afloramentos com cerca de 50 km de comprimento.

A partir das áreas de afloramento, as formações constituintes do SAG mergulham para leste em direção à área central da Bacia do Paraná, estando recobertas pelos basaltos da Formação Serra Geral, que chegam a apresentar espessuras superiores a 1000 metros próximos à calha do Rio Paraná, e pelos sedimentos relacionados ao Grupo Bauru (SANESUL/TAHAL, 1998).

Atualmente, cerca de uma centena de poços tubulares profundos captam água do Sistema Aqüífero Guarani para abastecimento público, rural e industrial no Estado de Mato Grosso do Sul, sendo responsáveis pelo fornecimento de aproximadamente $47.000 .000 \mathrm{~m}^{3} / \mathrm{ano}$ de água para a população do estado (CHANG, 2001).

Segundo SANESUL/TAHAL (1998), os poços perfurados no Sistema Aqüífero Guarani apresentam vazões variando de alguns metros cúbicos por hora até $320 \mathrm{~m}^{3} / \mathrm{h}$, com grande número deles apresentando vazões de até $40 \mathrm{~m}^{3} / \mathrm{h}$ (Figura 4).

Em função da ocorrência dos Sistemas Aqüíferos Serra Geral e Bauru, sobrepostos ao SAG em grande parte do Estado de Mato Grosso do Sul, a maioria dos poços tubulares profundos perfurados encontra-se próximo à área de afloramento, onde o SAG apresenta-se livre ou a cobertura basáltica é pequena. Os poços normalmente apresentam penetração parcial, e apenas recentemente os projetos construtivos passaram a prever a instalação de filtros ao longo de todo o aqüífero, de modo a obterem-se maiores vazões.

Os parâmetros hidráulicos do Sistema Aqüífero Guarani para o Estado de Mato Grosso do Sul, obtidos a partir da análise de ensaios de bombeamento realizados em poços tubulares disponíveis, indicam vazões específicas entre 1 e $7 \mathrm{~m}^{3} / \mathrm{h} / \mathrm{m}$ e transmissividades variando entre $10 \mathrm{e}$ $650 \mathrm{~m}^{2} /$ dia (SANESUL/TAHAL, 1998).

A análise da superfície potenciométrica do SAG na borda ocidental da Bacia do Paraná, foi elaborada a partir de dados contidos no estudo da SANESUL/TAHAL (1998), apresentados na tabela 1.

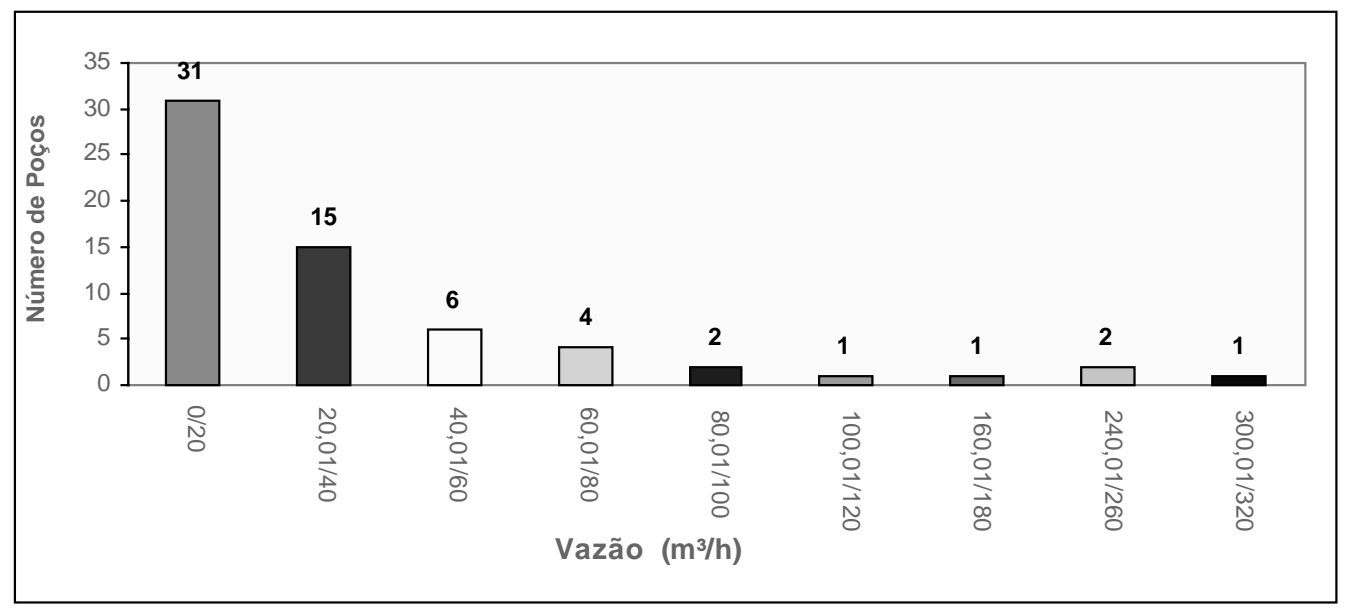

Figura 4 - Vazões dos Poços Perfurados no SAG -MS (Fonte: SANESUL/TAHAL, 1998) 


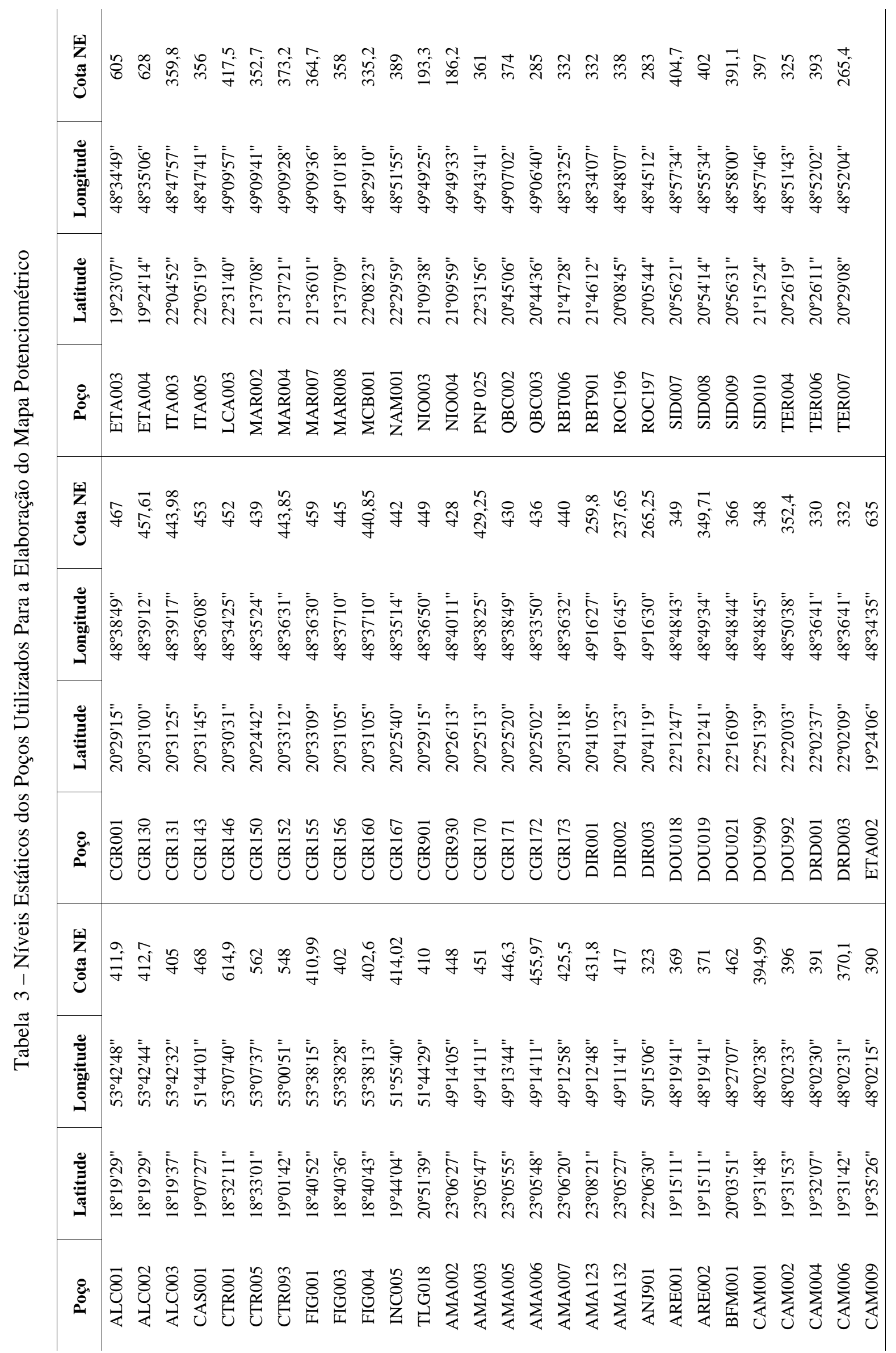


As condições de fluxo das águas subterrâneas do SAG no estado de Mato Grosso do Sul apresentam algumas peculiaridades quando relacionadas à borda leste da Bacia do Paraná, mais especificamente no estado de São Paulo, onde o fluxo das águas subterrâneas está direcionado a partir das áreas de afloramento, localizadas à leste deste estado, para oeste em direção ao eixo da Bacia do Paraná.

No Estado de Mato Grosso do Sul nota-se que o sentido do fluxo a partir das áreas de recarga é radial, em direção ao centro da Bacia do Paraná, onde o aqüífero encontra-se em condições de confinamento, e em direção às áreas de afloramento das formações Botucatu e Pirambóia que representam zonas de descarga locais, alimentando às bacias hidrográficas dos rios Aquidauana, Taquari e Coxim (Figura 5).

São distinguidas três zonas principais de recarga. A primeira encontra-se ao norte da área estudada, no Estado de Goiás, com fluxo direcionado para sul do Estado e também para oeste em direção à região de afloramentos das formações constituintes do SAG, alimentando os rios Coxim e Taquari, formadores do Pantanal Matogrossense.

A segunda área de recarga do aqüífero está localizada na região sul do Estado, próxima aos municípios de Ponta Porã e Amambaí, e ao sul do município de Dourados, com fluxo das águas subterrâneas direcionada para leste e nordeste em direção ao Estado do Paraná, e à confluência dos rios Paraná e Paranapanema, e uma segunda direção do fluxo para oeste, também no sentido das zonas de afloramento das formações Botucatu e Pirambóia.

A terceira área de recarga está relacionada ao Chapadão de São Gabriel D’Oeste, uma área topograficamente mais elevada, localizada na porção central do Estado, com fluxo radial em direção às zonas de afloramento localizadas a norte e sul, e em direção leste para a calha do Rio Paraná.

Associado a esta configuração de fluxo das águas subterrâneas, observa-se a existência de um divisor de águas subterrâneas, posicionado, grosso modo, subparalelo a borda ocidental do SAG, divisor este, provavelmente, controlado pelas áreas de recarga localizadas ao norte a sul do Estado.

\section{HIDROQUÍMICA DO SISTEMA AQUÍFERO GUARANI NO ESTADO DE MATO GROSSO DO SUL}

A partir dos resultados das análises físicoquímicas de amostras de água, apresentados em trabalhos anteriores por SANESUL/TAHAL (1998) e LASTORIA (2002), foi efetuada a avaliação e classificação hidroquímica das águas contidas no Sistema Aqüífero Guarani no Estado de Mato Grosso do Sul (Tabela 3).

Em função das características construtivas e do posicionamento geológico dos poços tubulares profundos, as amostras coletadas foram classificadas em três grandes grupos: SAG Aflorante, que agrupa as amostras de água coletadas nos poços localizados nas zonas de afloramento das formações Botucatu e Pirambóia; SAG Confinado, agrupando as amostras onde o SAG encontra-se confinado pelos derrames basálticos da Formação Serra Geral, com captação de água exclusiva do SAG garantida pelas características construtivas dos poços e um terceiro grupo, denominado de SAG Mistos, onde a penetração no SAG é parcial, a espessura de basaltos sobrepostos normalmente é pequena, e os poços geralmente não são revestidos.

As análises utilizadas para este estudo apresentaram erros de balanço iônico variando entre $7 \%$ e $60 \%$, aceitáveis para fins de classificação hidroquímica, quando se empregam os diagramas de Piper e Stiff.

A maioria das águas do SAG no Estado de Mato Grosso do Sul é classificada como bicarbonatada cálcica e subordinamente como bicarbonatada sódica.

O Diagrama de Pipper (Figura 6) mostra claramente a separação dos três grupos de águas contidas no SAG; as águas dos poços localizados na zona de afloramento (SAG Aflorante) são claramente bicarbonatadas cálcicas, com algumas amostras apresentando enriquecimento em cloretos, fato este que pode corroborar a teoria do enriquecimento em cloretos a partir de depósitos evaporíticos associados à formação Pirambóia, proposta por SRACECK; HIRATA (2002), feita para o Estado de São Paulo. 

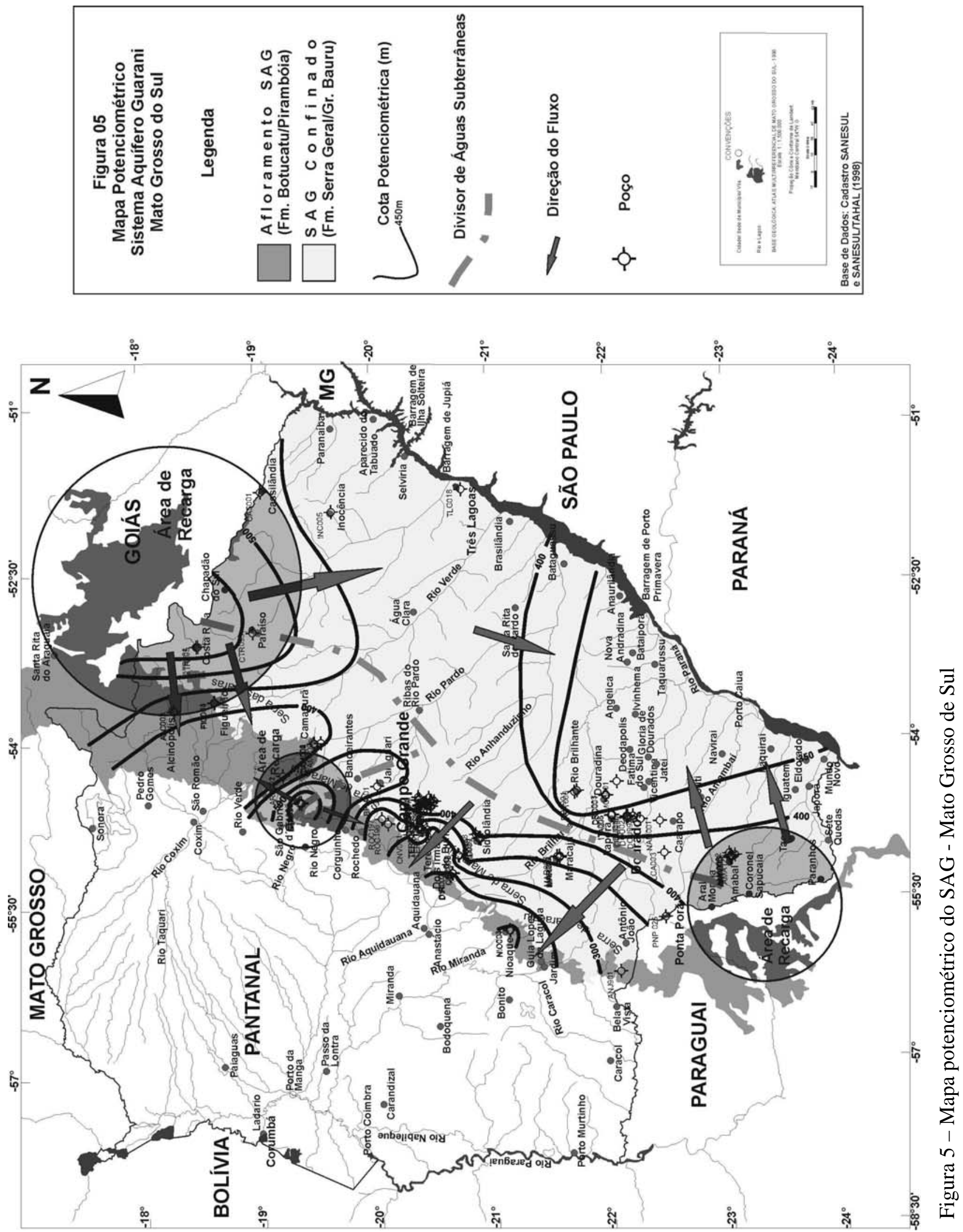

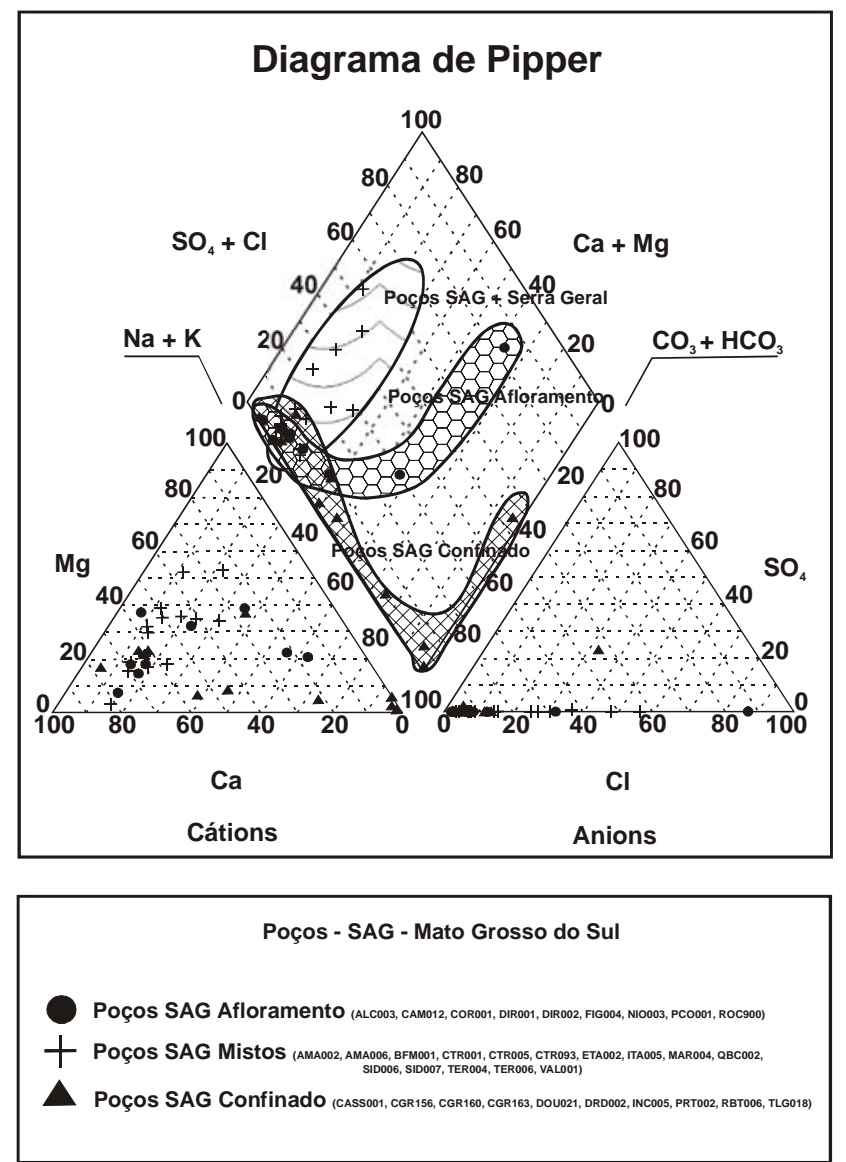

Figura 6 - Diagrama de Pipper com os grupos de água contidos no SAG em Mato Grosso do Sul

A figura 7 apresenta a variação das fácies hidroquímicas dentro do SAG no estado de Mato Grosso do Sul, mostrando uma tendência de aumento das salinidades a partir das áreas de recarga, situadas ao norte e ao sul do estado, e na região do município de São Gabriel D’Oeste, em direção a zona de maior confinamento do aqüífero, no centro da Bacia.

É interessante observar que este padrão, inferido através da variação da salinidade, é praticamente concordante com o padrão de fluxo derivado da potenciometria dos poços, apresentado no mapa da figura 5 .

As amostras coletadas em poços localizados nas áreas de afloramento das formações Botucatu e Pirambóia, ou próximos a elas (TER004 e 006, QBC002, CAM012, PCO001), apresentam teores em sais particularmente elevados, refletindo nestes casos a contribuição do cimento calcífero, cuja dissolução fornece o cátion cálcio e o ânion bicarbonato.
A passagem de águas bicarbonatadas cálcicas, próximas às zonas de recarga e de baixo confinamento do SAG, para águas bicarbonatadas sódicas, na região de Rio Brilhante, Douradina, Prudêncio Tomaz e Três Lagoas, área de maior confinamento do SAG, reporta a tendência já observada por SILVA (1983) para o estado de São Paulo.

As amostras coletadas em poços com águas classificadas como mistas, que captam águas dos aqüíferos Serra Geral e Guarani, apresentam águas bicarbonatadas cálcicas e magnesianas com alguma tendência de enriquecimento em magnésio, o que pode indicar contribuição das rochas basálticas na composição final das águas deste grupo.

As amostras de águas provenientes dos poços onde o SAG encontra-se sob condição de confinamento evoluem de águas bicarbonatadas cálcicas, coletadas próximo às zonas de recarga do aqüífero, para bicarbonatadas sódicas com o aumento das condições de confinamento. 
Tabela 3 - Parâmetros Físico Químicos das Águas do SAG - Mato Grosso do Sul

\begin{tabular}{|c|c|c|c|c|c|c|c|c|c|c|c|c|}
\hline Amostra & $\begin{array}{c}\text { Temp. } \\
\text { Água } \\
\left({ }^{\circ} \mathrm{C}\right)\end{array}$ & PH & $\begin{array}{c}\text { C. E. } \\
(\mu S / \mathrm{cm} \\
)\end{array}$ & $\begin{array}{c}\mathrm{Na}^{+} \\
(\mathrm{mg} / \mathrm{L})\end{array}$ & $\begin{array}{c}\mathrm{K}^{+} \\
(\mathrm{mg} / \mathrm{L})\end{array}$ & $\begin{array}{c}\mathrm{Ca}^{2+} \\
(\mathrm{mg} / \mathrm{L})\end{array}$ & $\begin{array}{c}\mathrm{Mg}^{2+} \\
(\mathrm{mg} / \mathrm{L})\end{array}$ & $\begin{array}{c}\mathrm{Cl}^{-} \\
(\mathrm{mg} / \mathrm{L})\end{array}$ & $\begin{array}{c}\mathrm{CO}_{3}^{-} \\
(\mathrm{mg} / \mathrm{L})\end{array}$ & $\begin{array}{l}\mathrm{HCO}_{3}^{-} \\
(\mathrm{mg} / \mathrm{L})\end{array}$ & $\begin{array}{l}\mathrm{SO}_{4}{ }^{2-} \\
(\mathrm{mg} / \mathrm{L})\end{array}$ & $\begin{array}{c}\mathrm{NO}_{3}^{-} \\
(\mathrm{mg} / \mathrm{L})\end{array}$ \\
\hline $\mathrm{ALC003}^{1}$ & 26 & 5,96 & 100 & 0,8 & 7,1 & 16,8 & 1,9 & 1,5 & 0 & 39 & 0 & 1,1 \\
\hline $\mathrm{AMA} 002^{1}$ & 23 & 6,2 & 120 & 3,9 & 1,2 & 9,2 & 4,6 & 5,5 & 0 & 14 & 0 & 3,6 \\
\hline AMA006 ${ }^{1}$ & 22 & 6,1 & 30 & 0,9 & 1,8 & 2 & 1,2 & 2 & 0 & 8 & 0 & 0 \\
\hline $\mathrm{BFM}_{001^{1}}$ & 25,5 & 6,5 & 150 & 3,8 & 1,1 & 21,6 & 7,3 & 2 & 0 & 45 & 0 & 1,4 \\
\hline CAM012 & 28,2 & 7,8 & 180 & 1,1 & 3,9 & 24 & 9 & 0,5 & 0 & 78 & 0 & 0 \\
\hline CASO01 $^{1}$ & 27,8 & 5,9 & 40 & 0,3 & 5 & 2 & 1,7 & 1,5 & 0 & 19 & 0 & 0 \\
\hline CGR156 ${ }^{2}$ & 30 & 7,4 & 121 & 2 & 3 & 12,95 & 2,68 & 3,2 & 0 & 85,4 & 0 & 8,5 \\
\hline CGR160 ${ }^{1}$ & 35 & 7,4 & 135 & 3,6 & 1,9 & 19,6 & 4,1 & 1,5 & 0 & 55 & 0 & 0,1 \\
\hline CGR163 $^{1}$ & 35 & 7,5 & 167 & 4,8 & 3,8 & 23,6 & 5,3 & 1,5 & 0 & 76 & 0 & 0,02 \\
\hline COR001 $^{1}$ & 26,5 & 6,2 & 70 & 0,5 & 6,2 & 6,8 & 3,1 & 1,5 & 0 & 25 & 0 & 0 \\
\hline CTR001 $^{1}$ & 24,5 & 6,9 & 90 & 2,1 & 0,9 & 11,2 & 3,4 & 2 & 0 & 47 & 0 & 0,5 \\
\hline CTR005 $^{1}$ & 26 & 6,5 & 60 & 1,9 & 1 & 7,2 & 1,2 & 2 & 0 & 22 & 0 & 0,2 \\
\hline CTR093 $^{1}$ & 25 & 5,5 & 25 & 0,7 & 0,3 & 2,8 & 1,2 & 1 & 0 & 11 & 0 & 0 \\
\hline DIR001 $^{1}$ & 26,8 & 6,3 & 20 & 0,6 & 2,5 & 1,2 & 1,2 & 1 & 0 & 11 & 0 & 0 \\
\hline DIR002 $^{2}$ & 27,4 & 5,4 & 39,5 & 3,29 & 1,28 & 0,96 & 0,7 & 1,8 & 0 & 2,5 & 0 & 16,6 \\
\hline DOU021 ${ }^{2}$ & 38 & 8,4 & 179 & 16 & 2 & 14,77 & 1,6 & 3,2 & 0 & 164 & 0 & 0 \\
\hline DOU021 $^{1}$ & 37,6 & 7,7 & 147 & 14,8 & 1,6 & 19,6 & 1,4 & 1 & 0 & 67 & 0 & 0 \\
\hline $\mathrm{DRD}^{2} 2^{1}$ & 27 & 6,8 & 177 & 36 & 1,1 & 10 & 1,2 & 2 & 0 & 75 & 0 & 0,4 \\
\hline $\mathrm{ETA} 002^{1}$ & 23 & 4,7 & 11 & 0,2 & 0,1 & 0,8 & 0,7 & 1,5 & 0 & 2 & 0 & 0 \\
\hline FIG004 & 27 & 6,9 & 100 & 1,9 & 3,9 & 19,6 & 1,2 & 1,5 & 0 & 43 & 0 & 0,4 \\
\hline${\text { INC } 005^{1}}^{1}$ & 33 & 7,5 & 280 & 1,4 & 2,2 & 39,2 & 5,8 & 1 & 0 & 107 & 0 & 0 \\
\hline${\text { ITA } 005^{1}}^{1}$ & 23 & 6,7 & 50 & 4,3 & 1,9 & 8,8 & 4,1 & 6 & 0 & 32 & 0 & 0,4 \\
\hline MAR004 $^{1}$ & 26 & 7,8 & 108,4 & 3,6 & 1,3 & 21,2 & 3,9 & 1,5 & 0 & 57 & 0 & 0 \\
\hline $\mathrm{NIO}^{1}$ & 26,5 & 6,5 & 144 & 3,9 & 2,2 & 16 & 2,9 & 2 & 0 & 45 & 0 & 0 \\
\hline $\mathrm{PCO} 01^{1}$ & 28 & 7,8 & 170 & 2,9 & 3,3 & 22 & 3,9 & 0,5 & 0 & 61 & 0 & 0 \\
\hline $\mathrm{PRT}^{2} 2^{2}$ & 35 & 9,5 & 398 & 100 & 0,75 & 0,5 & 0,02 & 3,55 & 0 & 300 & 1,2 & \\
\hline $\mathrm{QBC} 002^{2}$ & 31 & 6,34 & 361 & 6,5 & 3,58 & 33,8 & 16,5 & 18,5 & 0 & 171 & & 32,4 \\
\hline $\mathrm{RBT} 006^{1}$ & 30 & 9,4 & 140 & 44,9 & 0,6 & 0 & 1 & 1 & 20 & 51 & 1 & 0 \\
\hline ROC $900^{2}$ & 25 & 5,5 & 58 & 1 & 6 & 1,55 & 0,93 & 6,39 & 0 & 25 & 0 & 0,6 \\
\hline SID006 ${ }^{2}$ & 28,5 & 7,2 & 72,8 & 2 & 1 & 2,61 & 3,3 & 4,62 & 0 & 91,5 & 0 & \\
\hline $\mathrm{SID} 007^{1}$ & 27 & 8 & 180 & 4,1 & 1,4 & 25,2 & 3,6 & 0,5 & 0 & 73 & 0 & 0 \\
\hline TER004 $^{1}$ & 28 & 7,8 & 170 & 4,8 & 1,1 & 23,6 & 4,6 & 0,5 & 0 & 69 & 0 & 0 \\
\hline TER006 ${ }^{2}$ & 28,2 & 7,1 & 254 & 9,1 & 0,72 & 46,61 & 1,29 & 9,13 & 0 & 78,31 & 0,8 & 27,92 \\
\hline TLG018 $^{1}$ & 44,5 & 9,5 & 870 & 169,1 & 0,7 & 1,2 & 1,7 & 76,5 & 34 & 111 & 70 & 0 \\
\hline VAL001 $^{1}$ & 25 & 7,3 & 142,2 & 6,6 & 1,3 & 16,4 & 3,4 & 1,5 & 0 & 46 & 0 & 0,5 \\
\hline
\end{tabular}

C.E: Condutividade Elétrica

Fonte: ${ }^{1}$ - SANESUL/TAHAL (1998) , ${ }^{2}$ - LASTORIA (2002) 

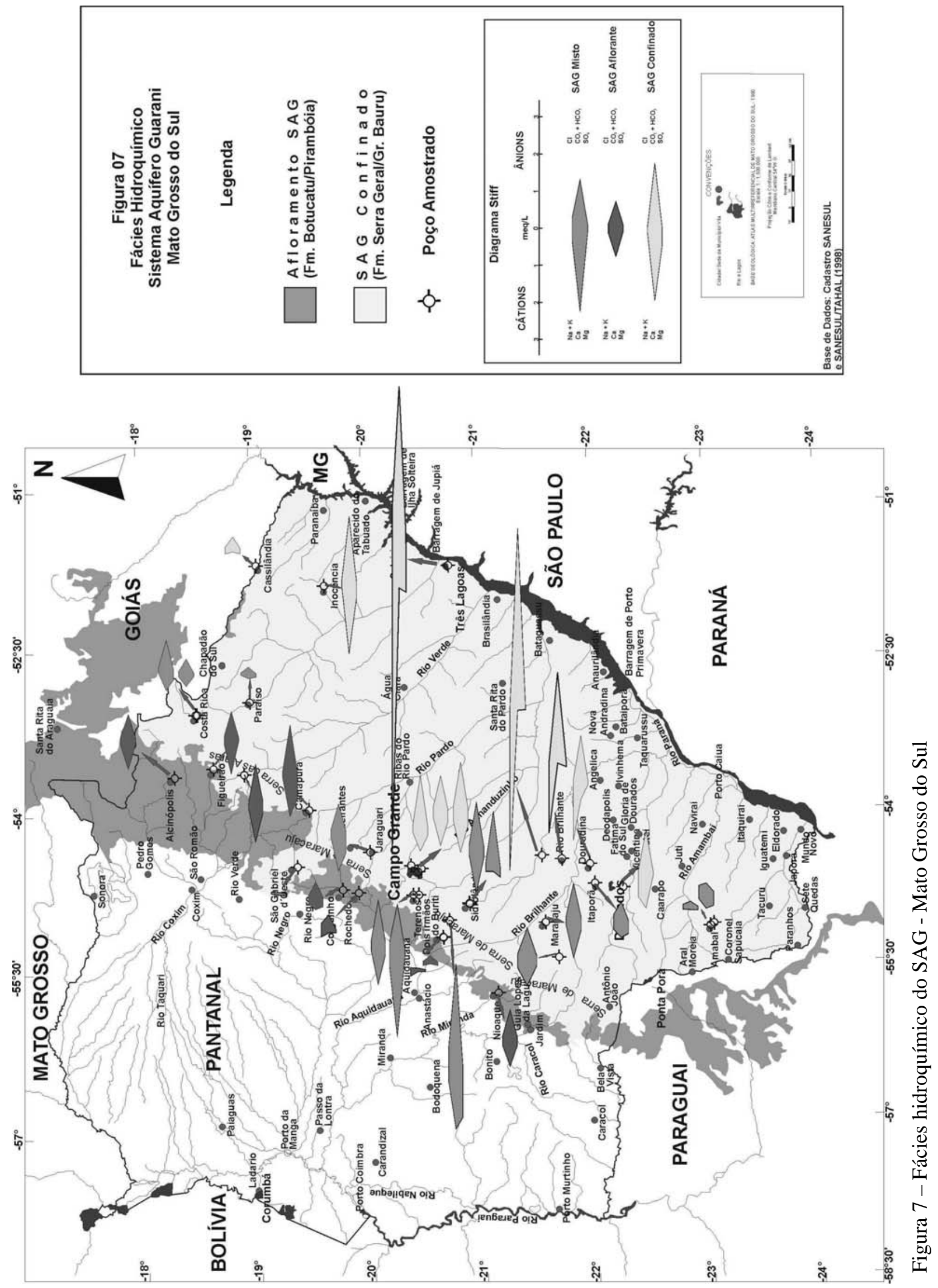


\section{CONCLUSÕES}

A análise preliminar dos dados existentes revela um comportamento distinto do fluxo de águas subterrâneas no Sistema Aquífero Guarani na borda ocidental da Bacia do Paraná, quando comparado com o seu comportamento na borda oriental, mais especificamente no Estado de São Paulo.

São identificadas áreas de recarga ao norte do Estado de Mato Grosso do Sul, nas regiões de afloramento das formações Botucatu e Pirambóia localizadas no Estado de Goiás, e ao sul do Estado, na fronteira com o Paraguai, onde também estão situadas áreas de afloramento. Já no lado matogrossense o aqüífero é sobreposto pelos derrames basálticos pertencentes à Formação Serra Geral.

Os fluxos de água subterrânea ocorrem a partir da zona de recarga, situada a norte de Mato Grosso do Sul, para sudoeste, em direção a bacia hidrográfica do Pantanal, e para sudeste, em direção a calha do Rio Paraná. O comportamento do fluxo das águas subterrâneas a partir da área de recarga, localizada ao sul do estado, também indica fluxo em direção ao Pantanal matogrossense e para o centro da Bacia do Paraná. A partir do alto localizado na região de São Gabriel d’Oeste, o fluxo das águas subterrâneas é radial.
Controlado por estas áreas de recarga observa-se a existência de um divisor de águas subterrâneas, paralelo a borda ocidental do SAG, no estado de Mato Grosso do Sul.

Em termos hidroquímicos, as águas subterrâneas contidas no SAG, no Estado do Mato Grosso do Sul, apresentam predominância do tipo bicarbonatada cálcica e, subordinadamente do tipo bicarbonatada sódica.

Acompanhando os sentidos de fluxo das águas subterrâneas observa-se que a evolução hidroquímica das águas se inicia com os termos bicarbonatados cálcicos, nas zonas de recarga e de baixo confinamento do SAG, passando a águas bicarbonatadas sódicas com o aumento das condições de confinamento, observando-se ainda um aumento dos teores de cloretos e sulfatos no poço de Três Lagoas, onde o topo do aqüífero encontra-se a 800 metros de profundidade.

\section{AGRADECIMENTOS}

Os autores agradecem ao Conselho Nacional de Pesquisa - CNPq, pela bolsa de estudos concedida através do processo 140471/2003-0, e à Empresa de Saneamento de Mato Grosso do Sul - SANESUL, através do geólogo Antônio Carlos Benatti, pela disponibilização da base de dados utilizada no desenvolvimento deste trabalho.

\section{REFERÊNCIAS}

ARAÚJO, L.M.; FRANÇA, A.B.; POTER, P.E. Aquífero Gigante do Mercosul no Brasil, Argentina, Uruguai e Paraguai; Mapas Hidrogeológicos das Formações Botucatu, Pirambóia, Rosário do Sul, Buena Vista, Missiones e Tacaurémbo. Mapas, UFPR PETROBRÁS, Curitiba, Texto Explicativo, 16p, 1995.

ARAÚJO, L.M.; FRANÇA, A.B.; POTER, P.E. Hydrogeology of the Mercosul Aquifer System in the Paraná and Chaco-Paraná Basins, South America, and comparison with the Navajo-Nugget Aquifer System, USA. Hydrogeology Journal, 7- p. 317-336, 1999.

CAMPOS, H.C.N.S. - Modelación Conceptual y Matemática del Aquífero Guarani, Cono Sur. Acta Geológica Leopoldinense - Série Mapas, XXIII (4) 3- 50, 2000.

CHANG, H. K. - Proteção Ambiental e Gerenciamento Sustentável Integrado do Aquífero Guarani-Tema 03, 2001 (Disponível em http://www.ana.gov.br/guarani/gestao/gest_cbasico. htm)
GALLO, G., SINELLI, O. - Estudo Hidroquímico e Isotópico das Águas Subterrâneas na Região de Ribeirão Preto (SP). Revista Brasileira de Geociências, V.10 p. 129 - 140, 1980.

GEF - BANCO MUNDIAL - OEA - Projeto de Proteção Ambiental e Gerenciamento Sustentável Integrado do Sistema Aquífero Guarani, Componente A, Atividade 1: Caracterização Física e Inventário de Poços, 94p, 2001. (Disponível em http:// www.ana.gov.br/guarani/gestao/gest_cbasico.htm). GILBOA, Y.; MERO, F.; MARIANO, I.B. - The Botucatu Aquifer of South América: Model of an Untaped Continental Aquifer. Journal of Hydrology, 29, 165 - 179, 1976.

KIMMELMANN e SILVA, A.A.; REBOUÇAS, A.C.; SANTIAGO, M.M.F.; SILVA, R.B.G. Isotopic Study of the Botucatu Aquífer System in the Brazilian Portion of the Parana Basin. In Isotope Hydrology Investigations in Latin America. IAEA TECDOC - 502, p. 51 - 71, 1987. 
KIMMELMANN e SILVA, A.A; FOSTER, M.; COELHO, R.O. - Environmental isotope and hydrogeochemical investigation of Baurú and Botucatú Aquifers, Parana Basin, Brazil. Isotope hydrology investigations in Latin America 1994. Results achieved during the implementation of the project RLA/8/014-ARCAL XIII: IAEA TECDOC- 835. p 57-74, 1995.

LASTORIA, G. - Hidrogeologia da Formação Serra Geral no Estado de Mato Grosso do Sul. Tese de Doutorado, IGCE/UNESP, Rio Claro, 197p, 2002.

MENG, S.X.; MAYARD, J.B. - Use of Statistical Analysis to Formulate Conceptual Models of Geochemical Behavoir: Water Chemical Data From the Botucatu Aquifer in São Paulo State, Brazil. Hydrogeology Journal, 250 (2001), 78 - 87, 2001. REBOUÇAS, A. C. - Sistema Aquífero Botucatu no Brasil. Anais $8^{\circ}$ Congresso Brasileiro de Águas Subterrâneas, Recife, 500 - 509, 1994.

ROSA FILHO, E.F. da; HINDI, E.C.; ROSTIROLLA, S.P.; FERREIRA, F.J.F.; BITTENCOURT, A.V.L. - Sistema Aquífero Guarani - Considerações Preliminares Sobre a Influência do Arco de Ponta Grossa no Fluxo das Águas Subterrâneas. Revista Águas Subterrâneas nº17, maio/2003, 91 - 111, 2003.
ROSA FILHO, E.F. da; SALAMUNI, R.; BITTENCOURT, A.V.L. - Contribuição ao Estudo das Águas Subterrâneas nos Basaltos do Estado do Paraná. Bol. Paranaense de Geociências $n^{0}$ 37, p. 22 - 52, 1987.

SANESUL/TAHAL - Estudos Hidrogeológicos de Mato Grosso do Sul. Relatório Final, Campo Grande, mapas V.I e II, 736p, 1998.

SEPLAN/CRN - Atlas Multireferrencial do Estado de Mato Grosso do Sul, Secretaria de Planejamento e Coordenação Geral, Coordenadoria de Recursos Naturais, Mapas, Campo Grande, 28p, 1990.

SILVA, R.B.G. da - Estudo Hidroquímico e isotópico do Aquífero Botucatu no Estado de São Paulo, Tese de Doutoramento, IG - USP, 133p, 1983.

SILVA, R.B.G. da; KIMMELMANN, A.A.; REBOUÇAS, A.C. - Estudo Hidroquímico e Isotópico das Águas Subterrâneas do Aquífero Botucatu - Resultados Parciais para a Região Norte da Bacia do Paraná. $5^{\circ}$ Simpósio Regional de Geologia, São Paulo. V.2, 489 - 502, 1985.

SRACEK, O.; HIRATA, R. - Geochemical and Stable Isotopic Evolution of the Guarani Aquifer System in the State of São Paulo, Brazil. Hydrogeology Journal, 10, 643 - 655, 2002. 